\title{
Intermédialités
}

Histoire et théorie des arts, des lettres et des techniques

Intermediality

History and Theory of the Arts, Literature and Technologies

\section{Nurith Aviv, Signer en langues (2016)}

\section{Myriam Suchet}

Numéro 27, printemps 2016

traduire

translating

URI : https://id.erudit.org/iderudit/1039817ar

DOI : https://doi.org/10.7202/1039817ar

Aller au sommaire du numéro

Éditeur(s)

Revue intermédialités (Presses de l’Université de Montréal)

ISSN

1920-3136 (numérique)

Découvrir la revue

Citer cet article

Suchet, M. (2016). Nurith Aviv, Signer en langues (2016). Intermédialités /

Intermediality, (27). https://doi.org/10.7202/1039817ar d'utilisation que vous pouvez consulter en ligne.

https://apropos.erudit.org/fr/usagers/politique-dutilisation/ 


\title{
Nurith Aviv, Signer en langues (2016)
}

\author{
MYRIAM SUCHET
}

- raduire » : le titre de ce numéro d'Intermédialités est identique à celui du troisième volet de la trilogie cinématographique de Nurith Aviv comprenant également D'une langue à l'autre (2004) et Langue sacrée, langue parlée (2008). Ce film donne à entendre dix traducteurs et traductrices qui témoignent de leur expérience de traduction de l'hébreu vers une autre langue. Chacun parle dans sa langue : Sandrick Le Maguer (français); Angel Sáenz-Badillos (espagnol); Yitshok Niborski (yiddish); Anna Linda Callow (italien); Sivan Beskin (russe); Manuel Forcano (catalan); Chana Bloch (anglais); Anne Birkenhauer (allemand); Rosie PinhasDelpuech (français); Ala Hlehel (arabe). Chaque séquence, qui nous mène dans un lieu différent (Brest, Boston, Malakoff, Milan, Tel Aviv, Barcelone, Berkeley, Jérusalem, Paris, Acre), s'ouvre sur le plan fixe d'une fenêtre. Puis, la lumière se fait sur le traducteur ou la traductrice qui sort, progressivement, de l'ombre. Cette « énonciation filmique $^{\mathrm{I}} \gg$ suggère beaucoup de ce qu'est l'acte de traduire. Les fenêtres, qui évoquent aussi les lettres hébräques, comme le souligne volontiers la réalisatrice, constituent selon moi l'envers (ou le négatif) de l'idée reçue selon laquelle chaque langue découperait une vision du monde qui serait singulière et de ce fait intraduisible ${ }^{2}$. Ici, aucune langue n'enferme dans un génie essentialisé, et la traduction, tout en étant incarnée et située, invite à regarder dehors.

Pour ce dossier d'artiste, nous avons opté pour une autre œuvre: Signer en langues, présentée du 14 décembre 2016 au 20 mars 2017 dans le cadre de l'exposition Après Babel, traduire sous le commissariat de Barbara Cassin. Comme je l'explique

I Olivier Beuvelet, «La scansion d'une parole filmique dans le cinéma de Nurith Aviv », Hypothèses: La parole des images. À la croisée des mots et des images par Olivier Beuvelet, 20 octobre 20I4, https://veraicona.hypotheses.org/ı2 (consultation le Io février 2017).

2 Pour une critique plus argumentée, voir Gaëtan Tröger, «Contribution à une épistémologie de la traduction : pour une explicitation des présupposés théoriques », Meta, vol. $49, \mathrm{n}^{\circ} 4,2004$, p. 747-767. 
dans l'introduction générale, ce court métrage met en scène Emmanuelle Laborit signant un même terme dans plusieurs langues des signes - dans les deux extraits disponibles ici, il s'agit de l'adjectif « bleu » et l'expression « faire l'amour » (voir les figures ret 2). Bien que seule la dimension iconique soit convoquée dans ces traductions, qui ne mettent pas en jeu la syntaxe et ne constituent pas une création en langue signée ${ }^{3}$, il m'a semblé que cette œuvre de Nurith Aviv pouvait entrer en résonance avec l'article de Julie Chateauvert et contribuer à décloisonner la réflexion entre langues parlées et signées.

J'ai également souhaité faire écho, dans l'espace de ce numéro d'Intermédialités, à cet autre dispositif de réflexion qu'est l'exposition. Le « tournant curatorial » de la recherche, remarqué par des commissaires et des artistes comme Aliocha Imhoff et Kantuta Quiros, n'est pas sans rapport avec la traduction :

Qu'est-ce que le curating ? Une première définition temporaire qui excède la simple mise en scène d'œuvres d'art pourrait être, a minima, une mise en relation de pratiques et de discours, produisant des cartographies cognitives. Il semble, en effet, que ce que nous appelons curating — dont les pratiques sillonnent entre autorité scientifique (suivant la filiation historique du conservateur de musée) et auctorialité (suivant le paradigme du curateur comme auteur), jouant parfois de ce double statut - relève avant tout d'opérations de connexion, de spatialisation, de montage, d'agencement, de traduction, que nous pourrions qualifier de pratiques de l'interstice 4 .

On pourrait ainsi considérer qu'exposer, en tant qu'acte d'agencer des pensées sensibles, est une forme de traduction. Sans doute faudrait-il préciser que la traduction dont il s'agit est intermédiale, puisqu'il s'agit de mettre en relation des espaces, des œuvres, des artefacts, des discours et des temporalités dont les matérialités spécifiques sont mises en avant. Consacrer une exposition à l'acte de traduire revient, dès lors, à interroger la traduction à la puissance deux, puisqu'il s'agit à la fois de son objet et de son mode opératoire. Ne pourrait-on pas en dire de même de ce numéro « Traduire », qui associe l'espace des pages, le volume du numéro virtuel et la cartographie de la plateforme Insight pour déployer une réflexion critique, esthétique, polyphonique, hétérolingue et indisciplinaire?

3 Pour un aperçu de quelques œuvres en langues signées, vous pouvez visiter le blogue Une école $d u$ regard de Julie Chateauvert: https://ecoleduregard.wordpress.com/les-oeuvresetudiees/ (consultation le 25 janvier 20I7).

4 Aliocha Imhoff et Kantuta Quiros, « Curating research - Pour une diplomatie entre les savoirs », L'Art même, n 64, 2015, p. 3-4 (je souligne). 
Langue des signes

française

espagnole

italienne

algérienne

jordanienne

anglaise

américaine

russe

indienne

chinoise

japonaise

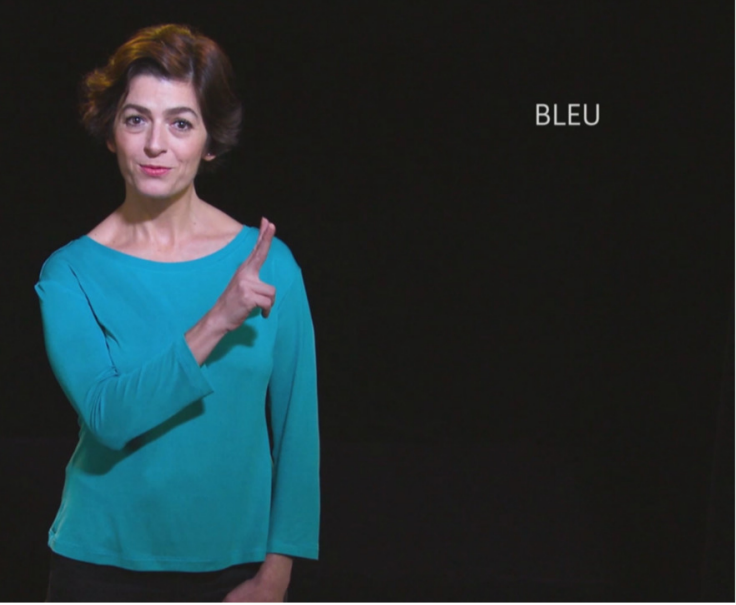

\footnotetext{
japonaise
}

Fig. I-2. «Bleu » (http://erudit.org/media/im/I0398I7ar/I039817arvoor.mp4) et «Faire l'amour » (http://erudit.org/media/im/I039817ar/I039817arvoo2.mp4), extraits du film Signer en langues, Nurith Aviv en collaboration avec Emmanuelle Laborit, Production Mucem/24 images, 2016. CEuvre présentée dans le cadre de l'exposition Après Babel, traduire, du I4 décembre au 20 mars 2017, Musée des civilisations de l'Europe et de la Méditerranée, Marseille, France.

(c) Nurith Aviv, 2016 


\section{NOTE BIOGRAPHIQUE}

Nurith Aviv a réalisé douze films, parmi lesquels une trilogie consacrée à « la langue » dont le dernier volet s'intitule Traduire (20II). Première femme à être reconnue comme directrice de la photographie par le Centre national du cinéma (France), elle a conçu l'image d'une centaine de films de fiction et de documentaires (pour, entre autres, Agnès Varda, Amos Gitaï, René Allio et Jacques Doillon). Elle enseigne dans des écoles de cinéma en France, en Allemagne et en Israël. Deux rétrospectives de ses œuvres ont eu lieu à Paris, à la Galerie nationale du Jeu de Paume en 2008 et au Centre GeorgesPompidou en 2015. Elle est aussi lauréate du prix Édouard-Glissant (2009). 